\title{
Eggplant Peel Ethanolic Extract: A Novel and Alternative Stain for Chromosome Banding
}

Hayfaa A Al-Shammary ${ }^{1}$, Rasha Salh² and Haidr Sabah ${ }^{2}$

${ }^{1}$ Medical Analysis Department, College of Science, University of the Qar, Iraq

${ }^{2}$ Biology Department, College of Science, University of the Qar, Iraq

\begin{abstract}
Rat and mouse have become important animal models to study various human diseases such as cancer. Here, we use eggplant peel ethanolic extract to visualise chromosome banding. This extract is easy to prepare, a novel, available alternative. The colour of this extract is bright dark green colour. This stain gave us good result for show the chromosomes banding, we used Thin Layer Chromatography (TLC) examination, Infrared (IR) spectroscopy and the spectrum ultraviolet UV to investigate about the compound and functional groups in this extract. Use of this extract represents a new method for chromosome banding and a viable alternative to existing chromosome staining methods.
\end{abstract}

Keywords: Ethanolic extract; Eggplant; Chromosomes bandings

\section{Introduction}

A wide variety of stains are used to visualise chromosomes under the microscope. The aceto-orcein, acetocarmine, gentian violet, and haematoxylin readily stain chromatin are classical cytological stains allowing for easy visualisation of chromosomes under a standard light microscope [1].

Numerous methods are available for identifying chromosomes and preparing karyotypes for clinical and research purposes. The most common methods of dye-based chromosome banding are Giemsa- $(\mathrm{G})$, reverse- $(\mathrm{R})$, centromere- $(\mathrm{C})$, and quinacrine- $(\mathrm{Q})$ banding. Q- and G-banding introduced a new era in which individual chromosomes could be definitively identified. With this capability, it also became possible to localize regions of variable size and staining to specific chromosomes. In particular, Q- and C-banding can reveal distinct classes of heteromorphisms that are not necessarily detectable in non-banded chromosomes. The most distinctive heteromorphism revealed by Q-banding was the brightly fluorescent distal long arm of the Y chromosome. The size of this brightly fluorescent segment varies from being almost negligible in size to being the longest segment on the $\mathrm{Y}$ long arm. Q-banding also revealed variations in staining of chromosomes $3,4,13-15$, and 21-22 of the human karyotype [26]. Although G-banding techniques have become widely used for chromosome identification, C-banding also revealed size variations of heterochromatin around the centromeres of every chromosome; these could be more easily quantified in banded than in non-banded chromosomes. The heterochromatin regions of chromosomes 1, 9, and 16 , and in the distal long arm of the $\mathrm{Y}$, evident in non-banded chromosomes, were especially visible by C-banding [6-10].Since banding may be a reflection of the difference in the structure along the length of a chromosome, studying the mechanism of banding can improve our understanding of chromosome structure [11-13]. Banding can be used for chromosome identification (karyotyping), and for identifying abnormalities of chromosome number, translocations of material from one chromosome to another, and deletions, inversions or amplifications of chromosomes. Q-banding was discovered by Caspersson et al. [2] who applied quinacrine mustard dihydrochloride (QM) staining to human chromosome $\mathrm{X}$. This resulted in the discovery that the end of the long arm of the $\mathrm{Y}$ chromosome was brightly fluorescent: bright enough that the human Y chromosome could be easily detected in interphase as well as in metaphase cells [14].
G-banding is the most widely used banding technique in clinical laboratories. The G-banding method uses acid fixation with saline treatment, followed by Giemsa staining [15]. Application of proteolytic enzymes such as trypsin $[16,17]$ or pancreatin $[18,19]$ improved the banding pattern. Dark-staining G-bands indicate AT-rich regions of chromosomal DNA that are more condensed replicate their DNA later than less condensed GC-rich regions [20].

R-banding was discovered by Utrillaux and Lejeune [21]. Due to technical difficulties and fluorescent requirements, it is not a widely used method of banding.

The observation by Pardue and Gall that the centromeres of mouse chromosomes stained darker than other chromosomal regions led to the discovery of C-banding [22]. Arrighi and Hsu [23,24] developed a modified technique C-banding by applying Giemsa staining; other modified versions of C-banding have since been developed.

The technique Cd-banding was described by Eiberg [25]. The G-11 technique and finally Silver Staining was developed by Howell and Black [27].

Eggplant, also called aubergine or brinjal (Solanum melongena L.) is an edible fruit, which is cultivated globally, but particularly in Asia and Europe $[28,29]$. Two kinds of anthocyanin have been isolated and identified from the purple cultivar [30,31]. The role of anthocyanin pigments as medicinal agents is well-accepted dogma in folk medicine throughout the world; indeed, eggplant is used in traditional medicines [30]. The anthocyanin delphinidin-3-rutinoside was identified from eggplant by HPLC-DAD-MS3 analyses [32]. A second anthocyanin, delphinidin-3-(p-coumaroylrutinoside)-5-glucoside (nasunin), was isolated as purple coloured crystals from eggplant peels [33].

*Corresponding author: Hayfaa A Al-Shammary, College of Science Medical Analysis Department, University of The Qar, Iraq, Tel: 078-017-897-65; E-mail: hayfaashamer@yahoo.com

Received October 16, 2014; Accepted January 22, 2015; Published January 26, 2015

Citation: Al-Shammary HA, Salh R, Sabah H (2015) Eggplant Peel Ethanolic Extract: A Novel and Alternative Stain for Chromosome Banding. J Bioprocess Biotech 5: 201 doi:10.4172/2155-9821.1000201

Copyright: (c) 2015 Al-Shammary HA, et al. This is an open-access article distributed under the terms of the Creative Commons Attribution License, which permits unrestricted use, distribution, and reproduction in any medium, provided the original author and source are credited. 


\section{Material and Methods}

\section{Ethanolic extract}

Eggplant peel was removed and dried in the shied. 25 grams of the resulting powder was extracted in $250 \mathrm{ml} 96 \%$ ethanol alcohol by using the socholite for 6 hours. The colour of this extract is bright dark green colour.

\section{Thin layer chromatography (TLC) examination}

TLC was carried out using ethyl acetate: hexane (1: 9) solvent. Chemical analysis with ethyl acetate: hexane (6:4) (1: 9) determined the presence of one separated compound (Figure 1).

\section{Infrared (IR) spectroscopy}

IR spectroscopy $(250-4500 \mathrm{~cm})$ indicated the presence of C-O,
$\mathrm{C}=\mathrm{O}, \mathrm{C}=\mathrm{C}, \mathrm{C}-\mathrm{H}$ and $\mathrm{CHO}=\mathrm{O}$ bonds, and the presence of benzene ring (Figure 2)

\section{The spectrum ultraviolet UV of Eggplant ethanolic extract}

Scan spectrum curve show the presence of absorption at the wavelength packages $(\max =200.00-780.00 \mathrm{~nm})$ has shown in Figure 3

\section{Cytogenetic examinations}

Rat chromosomes were prepared for cytogenetic examination. The animals were sacrificed and chromosome aberrations relieved using the method of Giri et al. [34]. Prepared slides were rinsed in ammonium alum solution for 2-3 minutes and stained for $15 \mathrm{~min}$ in an eggplant alcohol extraction solution. The staining solution was filtered immediately before use. Stained slides were air-dried before being examined and photographed under a light microscope.

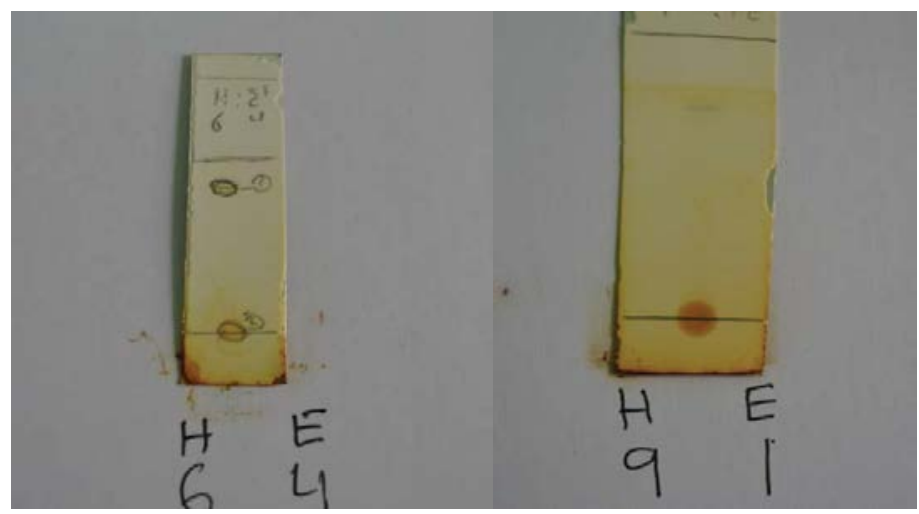

Figure 1: Location of the standards on the thin layer chromatography plate using hexane:ethanol (6:4) (1:9) as the mobile phase

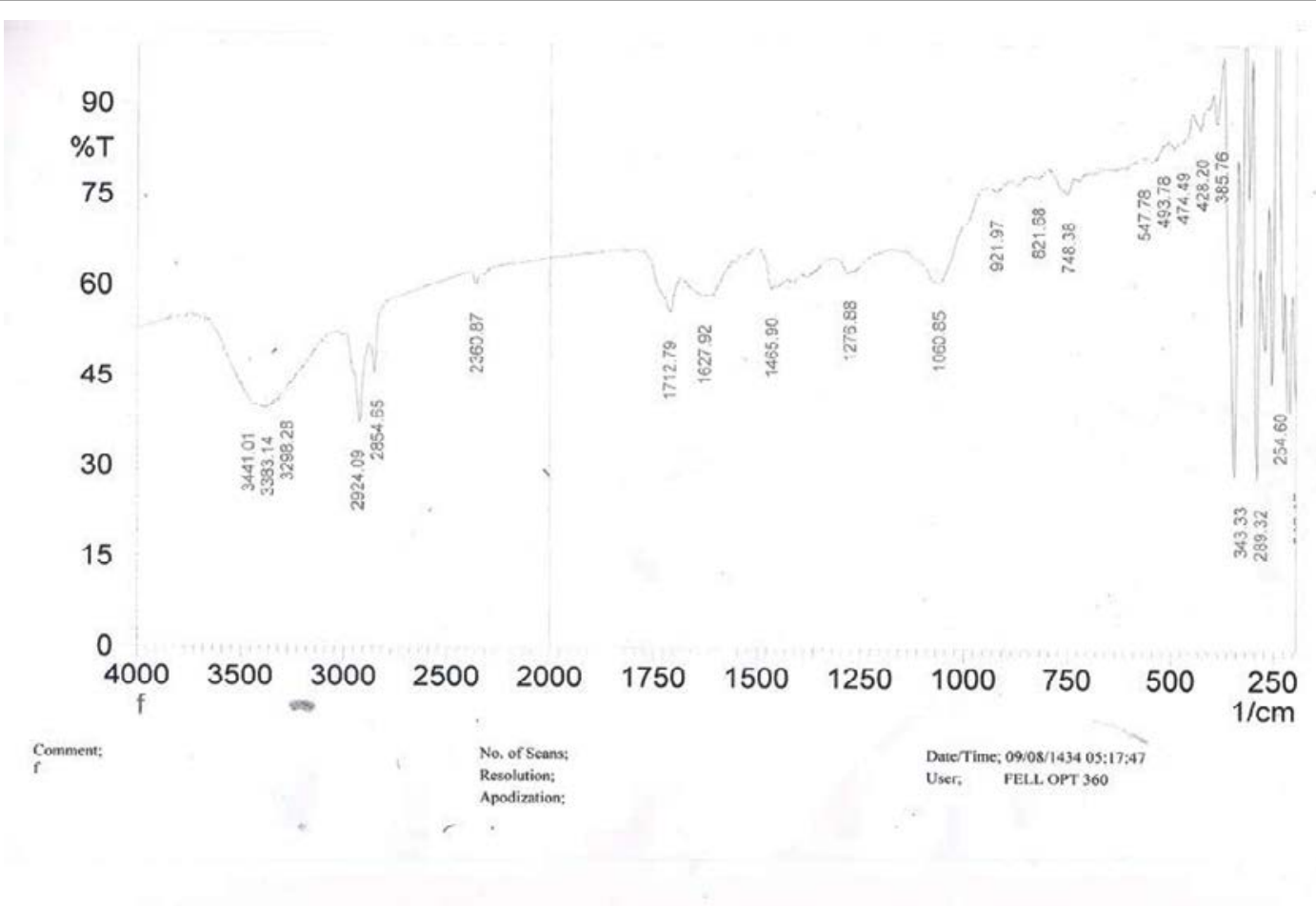

Figure 2: Infrared (IR) spectroscopy of Eggplant ethanolic extract 


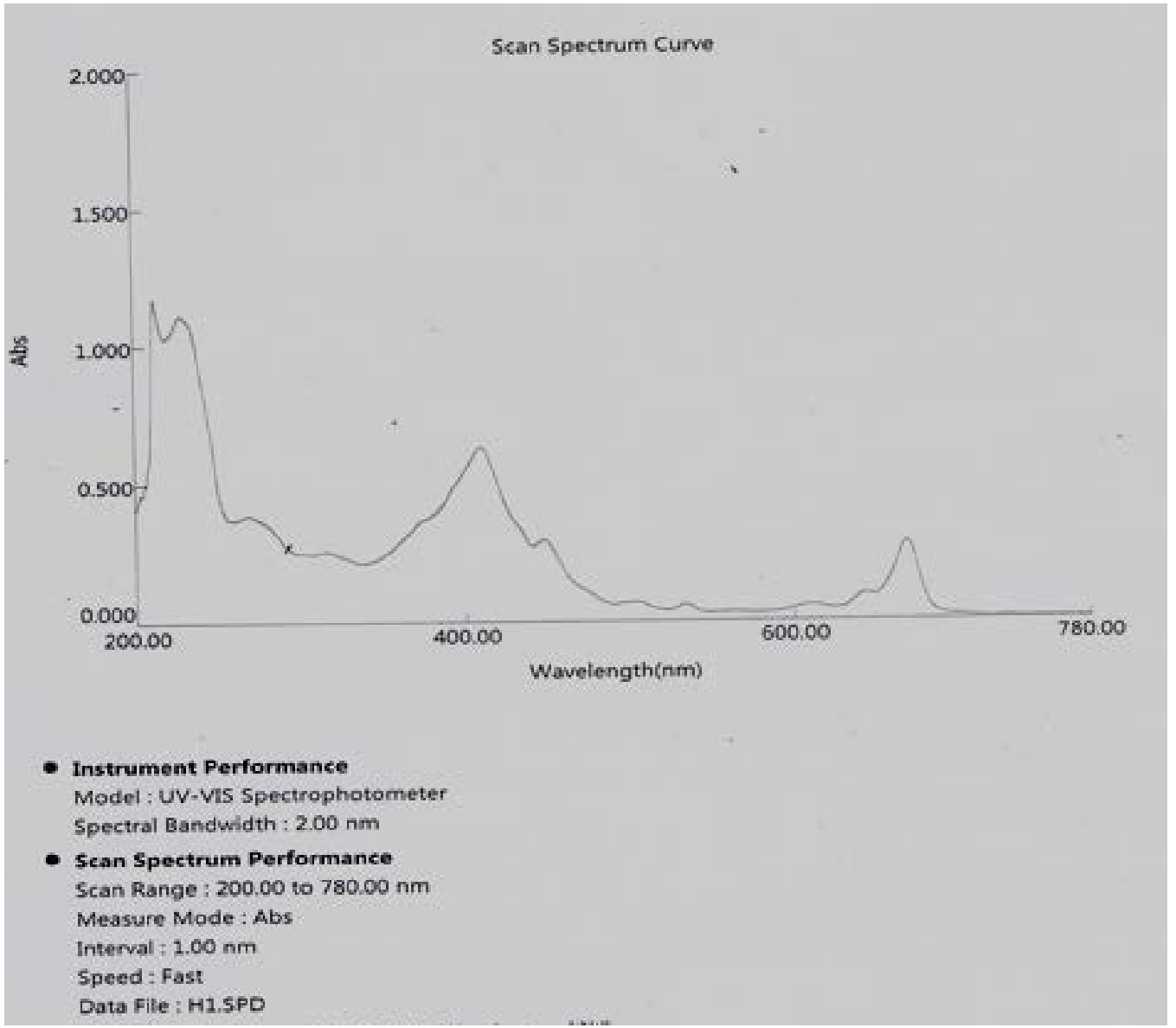

Figure 3: The spectrum ultraviolet UV of Eggplant ethanolic extract
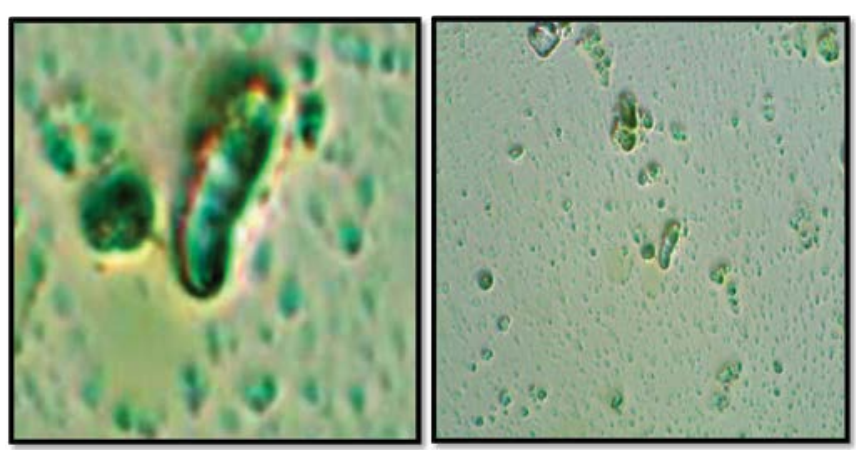

Figure 4A 4B: Normal rat male metaphase spread chromosome stained with eggplant peel ethanolic extract (800X) and (300X)

\section{Results}

As shown in Figure 4, stained chromosomes, with banding, could be clearly visualised after treatment with eggplant peel ethanolic extract, and Figure 5 which stained with Gemza shows no banding.

\section{Discussion}

Chromosome staining is used to enhance the contrast between different cellular components. Each chromosome arm is divided into regions, or cytogenetic bands, that can be seen using a microscope and special stains. The cytogenetic bands are labelled p1, p2, p3, q1, q2, q3, etc., counting from the centromere out toward the telomeres. These bands provide further information about the chromosomes. Since each chromosome number produces unique bands, this method can be used to identify individual chromosomes [35].

The result of this study showed that staining with eggplant alcohol extract is a viable method of staining rat chromosomes, and produced visible banding regions. In normal chromosomal stain procedure, metaphase chromosomes are treated with trypsin and stained with Giemsa stain. The major bands regions in chromosome are constitutive heterochromatin, facultative heterochromatin, and euchromatin. Heterochromatic regions, which tend to be ATrich and relatively gene-poor, stain more darkly in G-banding. In contrast, less condensed chromatin, which tends to be GC-rich and more transcriptionally active, incorporates less Giemsa stain, and hence these regions appear as light bands in G-banding. In this study ammonium alum solution has been used. This compound may bind to the DNA through intercalation, minor or major groove binding, or external binding, and thus have an effect on the nucleotides in the DNA. The mode of binding depends on the nature of the interaction between the stain and the DNA, which may be either covalent or noncovalent [35].

Using IR spectroscopy (IR ), we detected the presence of functional groups including $\mathrm{C}-\mathrm{O}, \mathrm{C}=\mathrm{O}, \mathrm{C}=\mathrm{C}, \mathrm{C}-\mathrm{H}, \mathrm{COH}=\mathrm{O}$ and benzene ring . This range of functional groups could produce more than one type of DNA-stain interaction, suggesting that our eggplant alcohol extract 
Citation:Al-Shammary HA, Salh R, Sabah H (2015) Eggplant Peel Ethanolic Extract: A Novel and Alternative Stain for Chromosome Banding. J Bioprocess Biotech 5: 201 doi:10.4172/2155-9821.1000201

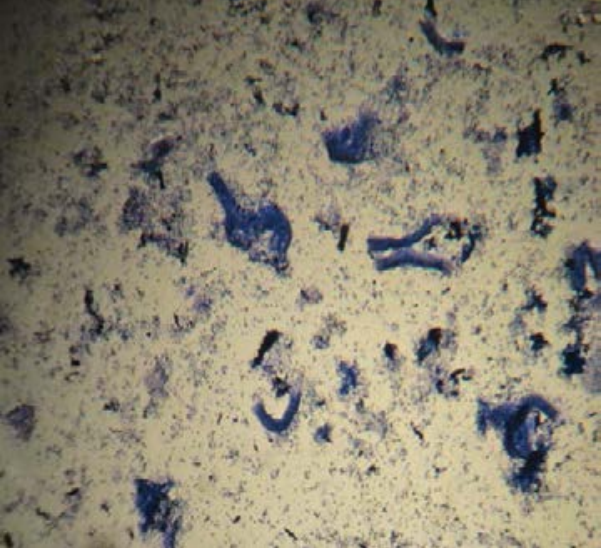

Figure 5: Normal rat male metaphase spread chromosome stained with Gemsa stain (300X)

stain can bind to DNA through several different binding modes [36]. The type of bands produced may also depend on the extent of denaturation undergone by the chromosome structure.

\section{Acknowledgements}

We would like to thank the college of science from the University of The Qar for facilitates and our families for the support they gave us.

\section{References}

1. Moore CM, Best RG (2001) Chromosome Preparation and Banding. Encyclopedia of life science. Nature Publishing Group. John Wiley \& Sons, Ltd.

2. Caspersson T, Farber S, Foley GE, Kudynowski J, Modest EJ, et al. (1968) Chemical differentiation along metaphase chromosomes. Exp Cell Res 49: 219-222.

3. Caspersson T, Zech L, Johansson C (1970) Analysis of human metaphase chromosome set by aid of DNA-binding fluorescent agents. Exp Cell Res 62 : 490-492.

4. Geraedts JP, Pearson PL (1974) Fluorescent chromosome polymorphisms: frequencies and segregations in a Dutch population. Clin Genet 6: 247-257.

5. Lin CC, Gedeon MM, Griffith P, Smink WK, Newton DR, et al. (1976) Chromosome analysis on 930 consecutive newborn children using quinacrine fluorescent banding technique. Hum Genet 31: 315-328.

6. Lubs HA, Patil SR, Kimberling WJ, Brown J, Cohen M, et al. (1977) Q and C-banding polymorphisms in 7 and 8 year old children: racial differences and clinical significance. In: Hook EB, Porter IH (editors) Population cytogenetic studies in humans. Academic Press, New York, USA, 133-150.

7. Craig-Holmes AP, Moore FB, Shaw MW (1973) Polymorphism of human C-band heterochromatin. I. Frequency of variants. Am J Hum Genet 25: 181 192

8. Müller H, Klinger HP, Glasser M (1975) Chromosome polymorphism in a human newborn population. II. Potentials of polymorphic chromosome variants for characterizing the idiogram of an individual. Cytogenet Cell Genet 15: 239 255.

9. McKenzie WH, Lubs HA (1975) Human Q and C chromosomal variations: distribution and incidence. Cytogenet Cell Genet 14: 97-115.

10. Magenis RE, Palmer CG, Wang L, Brown M, Chamberlin J, et al. (1977) Heritability of chromosome banding variants. Hook EB, Porter IH (editors) Population cytogenetics. Studies in humans. Academic Press, New York, USA, 179-188.

11. Hoshi O, Ushiki T (2001) Three-dimensional structure of G-banded human metaphase chromosomes observed by atomic force microscopy. Arch Histol Cytol 64: 475-482.

12. Sumner AT (1982) The nature and mechanisms of chromosome banding Cancer Genet Cytogenet 6: 59-87.
13. Saitoh Y, Laemmli UK (1994) Metaphase chromosome structure: bands arise from a differential folding path of the highly AT-rich scaffold. Cell 76: 609-622.

14. Caspersson T, Zech L, Johansson C (1970) Analysis of human metaphase chromosome set by aid of DNA-binding fluorescent agents. Exp Cell Res 62 : 490-492.

15. Drets ME, Shaw MW (1971) Specific banding patterns of human chromosomes Proc Natl Acad Sci U S A 68: 2073-2077.

16. Seabright $M$ (1971) A rapid banding technique for human chromosomes Lancet 2: 971-972.

17. Wang HC, Fedoroff S (1972) Banding in human chromosomes treated with trypsin. Nat New Biol 235: 52-54.

18. Müller W, Rosenkranz W (1972) Rapid banding technique for human and mammalian chromosomes. Lancet 1: 898.

19. Pearson $P$ (1972) The use of new staining techniques for human chromosome identification. J Med Genet 9: 264-275.

20. Sumner AT (1994) Chromosome banding and identification absorption staining In: Gosden GR (ed) Methods in molecular biology. Humana Press, Totowa, USA, 59-81.

21. Utrillaux B, Lejeune J (1971) [A new technic of analysis of the human karyotype] C R Acad Sci Hebd Seances Acad Sci D 272: 2638-2640.

22. Pardue ML, Gall JG (1970) Chromosomal localization of mouse satellite DNA Science 168: 1356-1358

23. Arrighi FE, Hsu TC (1971) Localization of heterochromatin in human chromosomes. Cytogenetics 10: 81-86.

24. Hsu TC, Arrighi FE (1971) Distribution of constitutive heterochromatin in mamallian chromosomes. Chromosoma 34: 243-253.

25. Eiberg H (1974) New selective Giemsa technique for human chromosomes, Cd staining. Nature 248: 55

26. Patil SR, Merrick S, Lubs HA (1971) Identification of each human chromosome with a modified Giemsa stain. Science 173: 821-822.

27. Howell WM, Black DA (1980) Controlled silver-staining of nucleolus organize regions with a protective colloidal developer: a 1-step method. Experientia 36: 1014-1015.

28. Lawande KF, Chavan JK (1998) Eggplant (Brinjal). In: Salunkhe DK, Kadam SS, (editors). Handbook of Vegetable Science and Technology: Production Composition, Storage, and Processing. Marcel Dekker, New York, pp 225-244.

29. Kashyap V, Kumar SV, Collonnier C, Fusari F, Haicour R, et al. (2003) Biotechnology of eggplant. Sci Hortic 2: 1-25.

30. Lans C (2007) Comparison of plants used for skin and stomach problems in Trinidad and Tobago with Asian ethnomedicine. J Ethnobiol Ethnomed 3: 3.

31. Zhang Y, Hu Z, Chu G, Huang C, Tian S, et al. (2014) Anthocyanin accumulation and molecular analysis of anthocyanin biosynthesis-associated genes in eggplant (Solanum melongena L.). J Agric Food Chem 62: 2906-2912.

32. Sadilova E, Stintzing FC, Carle R (2006) Anthocyanins, colour and antioxidan properties of eggplant (Solanum melongena L.) and violet pepper (Capsicum annuum L.) peel extracts. Z Naturforsch C 61: 527-535.

33. Noda Y, Kneyuki T, Igarashi K, Mori A, Packer L (2000) Antioxidant activity of nasunin, an anthocyanin in eggplant peels. Toxicology 148: 119-123.

34. Giri AK, Talukder G, Sharma A (1986) Sister chromatid exchange induced by metanil yellow and nitrite singly and in combination in vivo on mice. Cancer Lett 31: 299-303.

35. Estandarte AKC (2012) A review of the different staining techniques for human metaphase chromosomes. Thesis, University of London.

36. Ma DL, Che CM (2003) A bifunctional platinum(II) complex capable of intercalation and hydrogen-bonding interactions with DNA: binding studies and cytotoxicity. Chemistry 9: 6133-6144. 